The Review of Economic Studies Ltd.

\author{
A Multistage Model of Bargaining \\ Author(s): Joel Sobel and Ichiro Takahashi \\ Source: The Review of Economic Studies, Vol. 50, No. 3 (Jul., 1983), pp. 411-426 \\ Published by: The Review of Economic Studies Ltd. \\ Stable URL: http://www.jstor.org/stable/2297673 \\ Accessed: 07/12/2010 12:42
}

Your use of the JSTOR archive indicates your acceptance of JSTOR's Terms and Conditions of Use, available at http://www.jstor.org/page/info/about/policies/terms.jsp. JSTOR's Terms and Conditions of Use provides, in part, that unless you have obtained prior permission, you may not download an entire issue of a journal or multiple copies of articles, and you may use content in the JSTOR archive only for your personal, non-commercial use.

Please contact the publisher regarding any further use of this work. Publisher contact information may be obtained at http://www.jstor.org/action/showPublisher?publisherCode=resl.

Each copy of any part of a JSTOR transmission must contain the same copyright notice that appears on the screen or printed page of such transmission.

JSTOR is a not-for-profit service that helps scholars, researchers, and students discover, use, and build upon a wide range of content in a trusted digital archive. We use information technology and tools to increase productivity and facilitate new forms of scholarship. For more information about JSTOR, please contact support@jstor.org. 


\title{
A Multistage Model of Bargaining
}

\author{
JOEL SOBEL \\ and \\ ICHIRO TAKAHASHI \\ University of California, San Diego
}

\begin{abstract}
This paper presents a simple, multistage model of bargaining wherein a seller makes an offer that can be either accepted or refused. If rejected, the process continues. How the seller's ability to make commitments affects bargaining outcomes is analysed by comparing the commitment equilibria to those arising when commitment is impossible. The effects of increasing uncertainty about preferences and varying the length of the bargaining horizon are analysed. The ways in which the bargaining environment can be changed to improve outcomes are discussed.
\end{abstract}

\section{INTRODUCTION}

This paper considers a simple, asymmetric model of bilateral monopoly (bargaining) under uncertainty in which a single seller, with one object to sell, faces a single buyer. The seller announces a price for the object, which the buyer can either accept or reject. If the offer is accepted, then the object is transferred at the announced price; otherwise, the process continues with the seller announcing another price. Waiting is assumed to be costly to both buyer and seller. The one-period (stage) version of this model has been analysed by W. Samuelson (1980); Chatterjee and W. Samuelson (1981) consider the one-stage bilateral monopoly problem where both players make offers and a sale is made, at a compromise price, if the buyer offers at least as much as the seller.

Two aspects of the bilateral monopoly problem are of particular interest to us. First, if the seller has incomplete information about the buyer's willingness to pay, then there may be situations in which the buyer and seller fail to make a transaction at the first price even though gains from trade are available. Thus incomplete information about preferences may cause bargaining impasses. Impasses can take the form of costly delays before agreement is reached, or of an ex post inefficiency, the complete failure to make a beneficial transaction. If the seller realizes that there are unexploited opportunities for trade after the first offer is rejected, it is reasonable to assume that the bargaining process should continue; that is, bargaining should proceed in stages until all potential benefits are exhausted (in our model this takes the form of a sale being made or the discovery that no mutually beneficial sale is possible).

Once we assume that the bargaining takes place in stages, the second issue arises. What is the appropriate equilibrium concept? In principle, which bargainer makes offers should be determined endogenously. The assumption that only the seller makes offers allows us to draw conclusions about the sensitivity of outcomes to bargaining costs and the number of periods that are true in more general settings. One possibility is to look for strategies that maximize the expected profits of the seller assuming that the buyer, taking prices as given, buys in the period that maximizes his discounted surplus. We call these commitment equilibria; in such an equilibrium, the seller must be able to guarantee 
that the price schedule he originally announces will not be modified in the future. In general, such a position is not credible since optimal commitment strategies are time inconsistent: the seller will want to change his pricing policy after his first offer is rejected and he learns more about the buyer's willingness to pay. Alternatively, if commitment is not possible, the no-commitment equilibria are appropriate. Essentially, these consist of pricing plans that are optimal from each period forward conditional on the information the seller has learned by the buyer's previous refusal to make a purchase.

In this paper, the effects that the choice of equilibrium concept and uncertainty about preferences have on bargaining outcomes are analysed. Of particular interest are how outcomes change when bargaining costs, the number of periods, or the amount of uncertainty varies. An understanding of these effects might make it possible to design bargaining environments that lessen inefficiencies.

The results of the paper are as follows. Section 3 gives a characterization of equilibria in the two-stage game, examples to show that there are no general comparative-statics results for the no-commitment equilibria, and a theorem that suggests that bargaining outcomes can be improved by controlling the length and timing of the bargaining periods. ${ }^{1}$

Section 4 considers an analytically tractable class of examples. This class is rich enough to yield intuitively appealing sensitivity results as well as to suggest the conditions on which these results depend.

In addition to the papers of Samuelson (1980) and Chatterjee and Samuelson (1981), which show that uncertainty about preferences is a cause of bargaining inefficiency, other models that explain bargaining impasses have been proposed. General results that explain the failure to reach efficient outcomes in games with incomplete information have been given by Myerson (1979) and Rosenthal (1978). Crawford (1982) presents a model in which impasses are the result of bargainers commiting themselves to incompatible positions. In Crawford (1982), a bargainer makes a demand in the first period, then he learns his own cost of backing down, but not that of his opponent. In the second, and final, period the bargainer decides whether to back down from his demand based on his cost and the other bargainer's demand. Not backing down leads to an inefficient outcome if the other bargainer refuses to back down from an incompatible position, but leads to a high payoff if the other bargainer backs down. The ability to make successful commitments is determined endogenously in Crawford's model. Fudenberg and Tirole (1983) completely characterize the no-commitment equilibria in a two-stage bargaining model virtually identical to ours. Except for an example, they restrict attention to reservationprice distributions for both bargainers that have two-point supports. Fudenberg and Tirole's (1983) results will be contrasted with ours throughout the paper. Using a similar model, Crampton (1982) analyses a two-stage bargaining model with two-sided uncertainty and in which there is a continuum of potential buyer and seller reservation prices.

Several other papers deal with sequential bargaining or bargaining with incomplete information. Rubinstein (1982), Binmore (1980), and McLennan (1981), in related papers, consider bargaining processes that are in principle sequential. However, they assume complete information and, except for exceptional cases, bargaining terminates after a single period. In these models the relative cost of waiting determines bargaining strength. Riley and Zeckhauser (1980) consider a bargaining model in which the seller is allowed to commit himself and there are no costs associated with delaying agreement. They find that in general, a single take-it-or-leave-it price generates higher expected profit than making concessions over time. This result appears in our model as well (see Theorem 1). Finally, Myerson and Satterthwaite (1983) consider procedures that maximize the sum of buyer and seller surplus in a bilateral monopoly model similar to ours. These procedures are usually ex post inefficient so that they can only be sustained if the bargainers can commit themselves to discontinue negotiations if they fail at first to reach an agreement; explicit bargaining costs are not present. 


\section{THE MODEL}

There is a single buyer characterized by a reservation price $v$ and a discount factor $q$. There is a single seller characterized by a known reservation price taken, without further loss of generality, to be 0 and a discount factor $p$. The costs of bargaining are represented by $p$ and $q$; we assume $0<p, q<1$. Both discount factors are common knowledge; $v$ is known only to the buyer. A probability distribution $F(v)$, which is common knowledge, represents the belief that the seller has about the buyer's reservation price. $F(v)$ is the probability that the buyer has a reservation price less than or equal to $v$. We assume that $F(\cdot)$ is supported on $[0,1]$ and, for most of the paper, that the density function $f(v) \equiv F^{\prime}(v)$ is continuous and strictly positive for $v \in[0,1]$.

Bargaining has the following structure. The seller sets a price and offers the buyer an opportunity to purchase the object. The buyer then either waits or agrees to make the purchase at the given price. If the buyer refuses the offer then the process repeats, with the seller making a new offer in the next period. In Section 3 we assume that only two offers can be made; in Section 4 we assume that the process continues indefinitely.

We distinguish between two types of equilibria. The simplest is the commitment equilibria.

Definition. A commitment equilibrium for the $n$-stage bargaining game is a sequence of price functions $x_{1}^{*}, \ldots, x_{n}^{*}$ that maximize the seller's expected profit assuming that the buyer, taking prices as given, buys in the period that maximizes his discounted surplus.

Thus, $x_{1}^{*}, \ldots, x_{n}^{*}$ is a commitment equilibrium if $x_{1}^{*}, \ldots, x_{n}^{*}$ solve:

$$
\max _{x_{1}, \ldots, x_{n}} \sum_{i=1}^{n} p^{i-1} x_{i}\left(F\left(S_{i-1}\right)-F\left(S_{i}\right)\right)
$$

subject to $1 \geqq S_{i} \geqq S_{i+1} \geqq 0$ for $i=1, \ldots, n-1$ where

$$
S_{i}= \begin{cases}1 & \text { for } i=0, \\ \left(x_{i}-q x_{i+1}\right)(1-q)^{-1} & \text { for } i=1, \ldots, n-1, \\ x_{n} & \text { for } i=n .\end{cases}
$$

A $v$-buyer will prefer buying in period $i$ to period $i+1$ if $v-x_{i}>q\left(v-x_{i+1}\right)$ or $v>S_{i}$. It follows that period $i$ is a $v$-buyer's most preferred time to buy if $S_{i-1}>v>S_{i}$ and so $F\left(S_{i-1}\right)-F\left(S_{i}\right)$ is the ex ante probability of making a sale in the $i$ th period and $x_{i}\left(F\left(S_{i-1}\right)-F\left(S_{i}\right)\right)$ is the ex ante, undiscounted expected profit in stage $i$.

In a commitment equilibrium, the seller is able to stick to a particular sequence of prices in spite of what he learns from the buyer's actions.

In a more general model, the seller's ability to make commitments would be determined endogenously. However, the approach of this paper is to compare commitment equilibria to the outcomes that arise if commitment is impossible. This allows us to study how the gains from commitment vary with bargaining costs.

Let

$$
\pi_{1}(S) \equiv \max _{x}[x(F(S)-F(x))] F(S)^{-1}
$$

be the maximum expected profit of a seller if there is one period remaining and the buyer is known to have a reservation price no greater than $S$. Assume that $x(F(S)-F(x))$ is maximized by a unique value of $x$ for fixed $S^{2}$; let $x_{2}(S)$ denote that value of $x$.

Definition. ${ }^{3}$ A no-commitment equilibrium for the two-stage bargaining game consists of prices $\hat{x}_{1}$ and $\hat{x}_{2}$, a cut-off function $\hat{S}\left(x_{1}\right)$, and point expectations $E\left(x_{2} \mid x_{1}\right)$ 
such that

(i) $\hat{x}_{1}$ solves: $\max _{x_{1}} x_{1}\left(1-F\left(\hat{\boldsymbol{S}}\left(x_{1}\right)\right)\right)+p \pi_{1}\left(\hat{\boldsymbol{S}}\left(x_{1}\right)\right) F\left(\hat{\boldsymbol{S}}\left(x_{1}\right)\right)$

(ii) $\hat{x}_{2}=x_{2}\left(\hat{\boldsymbol{S}}\left(\hat{x}_{1}\right)\right)$

(iii) $E\left(x_{2} \mid x_{1}\right)=x_{2}\left(\hat{S}\left(x_{1}\right)\right)$,

(iv) $\hat{S}\left(x_{1}\right)=\left(x_{1}-q E\left(x_{2} \mid x_{1}\right)\right)(1-q)^{-1}$, and

(v) A $v$-buyer accepts the first offer of $x_{1}$ if and only if $v \geqq \hat{S}\left(x_{1}\right)$; a $v$-buyer who refused the first offer accepts the second offer, $x_{2}$, if and only if $v \geqq x_{2}$.

The buyer's decision of when to buy can be described by the $\hat{\hat{S}}(\cdot)$ function since, if an $\hat{S}$-buyer is indifferent between waiting and accepting the first offer, then a $v$-buyer strictly prefers to buy in the first period if and only if $v>\hat{S}$.

The difference between a no-commitment equilibrium and a commitment equilibrium is the added restriction that the seller's second-period price maximizes expected profit conditional on what he learns from the buyer's refusal to make a purchase in the first period. Unless the seller is able to prevent himself from doing so (by committing himself to another course of action), it is natural to require that he sets conditionally optimal second-period prices.

The no-commitment equilibria involve a phenomenon not present in the commitment equilibria, but present in real bargaining situations: information transmission. In order to formulate strategies, both the buyer and the seller must correctly use the information that their opponent's previous actions convey. Thus, the seller uses a failure to accept an offer as an indication that the buyer's reservation price is below a certain value; the buyer uses the first offer of the seller to make a prediction about future prices, and decide whether to wait or to accept the first offer.

Informally, a no-commitment equilibrium has this form. The buyer forms a conjecture about the relationship between the first offer and the seller's second offer. Acting on this conjecture, he can predict the expected value of the second offer given the first offer, $E\left(x_{2} \mid x_{1}\right)$, and thus decide whether to wait. Conditions (iv) and (v) guarantee that the buyer is purchasing in the correct period given his expectations. The seller, taking the buyer's behaviour as given and taking into account that his second offer is constrained to be conditionally optimal given the buyer's refusal in the first period (ii), decides which first offer to make (i). Finally, we require that the buyer's expectations are fulfilled in equilibrium (iii).

In Section 4 we analyse no-commitment equilibria for the $n$-stage game. The definition given above can be extended to this case. Formally, let

$$
\pi_{k}(S) \equiv \max _{x \leqq S}\left[x\left(F(S)-F\left(T_{k-1}(x ; S)\right)\right)+p \pi_{k-1}\left(T_{k-1}(x ; S)\right) F\left(T_{k-1}(x ; S)\right)\right] F(S)^{-1}
$$

where

and for $k>0$,

$$
\pi_{0}(S)=0, \quad T_{0}(x ; S)=\min [x, S],
$$

$$
T_{k}(x ; S) \equiv \begin{cases}T & \text { where } T \doteq\left(x-q r_{k}(T)\right)(1-q)^{-1} \text { if such a } T \in[0, S] \text { exists, } \\ S & \text { otherwise }\end{cases}
$$

and $r_{k}(S)$ is the value (it will be unique for our applications) of $x$ that maximizes

$$
x\left(F(S)-F\left(T_{k-1}(x ; S)\right)\right)+p \pi_{k-1}\left(T_{k-1}(x ; S)\right) F\left(T_{k-1}(x ; S)\right)
$$

subject to $x \leqq S$. Thus, when there are $k$ periods remaining and the buyer is known to have a reservation price no greater than $S, \pi_{k}(S)$ is the maximum expected profit assuming that the seller will behave optimally in the future; $r_{k}(S)$ is the price charged in order to attain $\pi_{k}(S)$ and $T_{k-1}(x ; S)$ is the reservation price that makes the buyer indifferent between waiting and accepting the offer $x$. For the examples of Section $4, r_{k}(\cdot)$ will be increasing and $r_{k}(x) \leqq x$, so that $T_{k}(\cdot)$ is well-defined and $T_{k}(x ; S) \geqq x$. Therefore, $\pi_{k}(\cdot)$ and $r_{k}(\cdot)$ can be defined inductively; the no-commitment equilibrium prices for the $n$-stage bargaining game are the prices charged in order to attain $\pi_{n}(1)$. 


\section{TWO STAGES}

In this section we examine the two-stage bargaining game.

First, we characterize the commitment equilibria.

Theorem 1. If $p \leqq q$, then there is a commitment equilibrium $\left(x_{1}^{*}, x_{2}^{*}\right)$ with $x_{1}^{*}=x_{2}^{*}$. If $p>q$, then all commitment equilibria involve $x_{1}^{*}>x_{2}^{*}$.

Proof. The seller's problem (A) is equivalent to finding an $S^{*}$ and an $x_{2}^{*}$ to solve:

$$
\max _{S, x_{2}}\left((1-q) S+q x_{2}\right)(1-F(S))+p x_{2}\left(F(S)-F\left(x_{2}\right)\right)
$$

subject to

$$
1 \geqq S \geqq x_{2} \geqq 0 .
$$

If $\left(S^{*}, x_{2}^{*}\right)$ solves $(\mathrm{B})$, then $x_{1}^{*}=(1-q) S^{*}+q x_{2}^{*}$ and $x_{2}^{*}$ solve (A). The objective function in (B) can be rewritten

$$
(1-q) S(1-F(S))+q x_{2}\left(1-F\left(x_{2}\right)\right)+(p-q) x_{2}\left(F(S)-F\left(x_{2}\right)\right) .
$$

When $p \leqq q$ and $S \geqq x_{2}$ the third term in (1) is non-positive. Therefore the entire expression is maximized when $S=x_{2}=\bar{x}$, where $\bar{x}$ is a solution to: $\max _{x} x(1-F(x))$, since in this case all three of the terms in the sum (1) are maximized. If $p>q$, (1) is either increasing in $S$ or decreasing in $x_{2}$ whenever $S=x_{2}$. Since the maximum is certainly not achieved for boundary values $\left(S=1\right.$ or $\left.x_{2}=0\right)$, the solution must involve $S>x_{2}$. These arguments establish the theorem because $x_{1}^{*}$ is a convex combination of $S^{*}$ and $x_{2}^{*}$.

When $p \leqq q$, Theorem 1 enables us to give the concept of commitment a clear, operational meaning. The seller maximizes his expected profits by announcing a take-itor-leave-it price. If the buyer is at least as patient as the seller, the benefits of charging a price low enough to make additional sales in the second period are outweighed by the losses that result when the buyer delays his purchase to take advantage of a lower second price. It should be emphasized that this strategy would not generally be an equilibrium without the possibility of commitment: if the optimal commitment policy is announced and the first offer is rejected, the seller will have an incentive to lower his price in order to make a sale to a low- $v$ buyer. The commitment equilibrium is only viable if the buyer is convinced that the seller will not deviate from his announced strategy.

That the optimal commitment strategy involves restricting sales to a single period when $p=q$ has been noted, in more general settings, by Stokey (1979), in the context of intertemporal price discrimination, and by Riley and Zeckhauser (1980) in a bargaining model. Fudenberg and Tirole (1983) noted that the single-price result does not hold when $p>q$.

We now examine the sensitivity of commitment equilibria to changes in parameters; since the single-price equilibrium obtains when $p \leqq q$, we restrict attention to $p>q$. Increases in the bargaining horizon from one to two periods strictly increase the expected profits of the seller since the one-period strategy is still feasible, but is not adopted; decreases in $q$ are beneficial to the seller because the same prices generate higher expected profit. Straightforward computations show that $S^{*}(\cdot)$ is decreasing in $q$ and increasing in $p$ when $p q^{-1}$ is close to one. The effect of changes in $p$ and $q$ on $x_{1}^{*}(\cdot)$ and $x_{2}^{*}(\cdot)$ is ambiguous. If $p=q$ an increase in $p$ reduces $x_{2}^{*}$ as does a decrease in $q$. However, if $p q^{-1}$ is large then the prices respond to changes in the bargaining costs in the same way as $S^{*}(\cdot)$. The expected surplus to the buyer, given prices $x_{1}$ and $x_{2}$, and 
$S=\left(x_{1}-q x_{2}\right)(1-q)^{-1}$, is

$$
\int_{S}^{1}\left(v-x_{1}\right) F^{\prime}(v) d v+q \int_{x_{2}}^{s}\left(v-x_{2}\right) F^{\prime}(v) d v .
$$

Substituting $(1-q) S+q x_{2}$ for $x_{1}$ in (2) yields

$$
B\left(S, x_{2}\right) \equiv(1-q) \int_{S}^{1}(v-S) F^{\prime}(v) d v+q \int_{x_{2}}^{1}\left(v-x_{2}\right) F^{\prime}(v) d v .
$$

In a commitment equilibrium, $B^{*}(p, q) \equiv B\left(S^{*}(p, q), x_{2}^{*}(p, q)\right)$ is decreasing in $p$ whenever $S^{*}(\cdot)$ and $x_{2}^{*}(\cdot)$ are increasing in $p$ since $B(\cdot)$ is decreasing in $S$ and $x_{2}$. That increases in $p$ and in the number of periods can actually benefit the buyer is shown in the example following Theorem 2. The example also shows that the first price in the two-stage commitment equilibrium may be higher or lower than the one-stage price.

The characterization of the commitment equilibria given above does not depend on bargaining being limited to two stages; the optimal selling strategy involves restricting sales to the first period if and only if $p \leqq q$ regardless of the number of periods. We have restricted attention to the two-stage model because it is only in this case that general analysis of no-commitment equilibria is possible for us.

To analyse the no-commitment equilibria, we assume that the function $G(x) \equiv x F(x)$ is twice continuously differentiable and that $G^{\prime \prime}(\cdot)>0$. This is a decreasing expected marginal revenue assumption, and guarantees that the problem

$$
\max _{x} x(F(S)-F(x))
$$

has a unique solution, $x_{2}(S)$, for each $S . x_{2}(S)$ is defined implicitly by the first-order condition for $(\mathrm{C})$,

$$
G^{\prime}\left(x_{2}(S)\right) \equiv F(S) .
$$

It follows that $x_{2}(\cdot)$ is strictly increasing and $S>x_{2}(S)>0$. If $\pi(S) \equiv$ $x_{2}(S)\left(F(S)-F\left(x_{2}(S)\right)\right) F(S)^{-1}$ is the maximum expected single-period profit given that $v \leqq S$, then a no-commitment equilibrium is characterized by a first-period price, $\hat{x}_{1}$, that solves:

$$
\max _{x} x(1-F(S(x)))+p \pi(S(x)) F(S(x))
$$

subject to

$$
S(x)= \begin{cases}S & \text { where } S=\left(x-q x_{2}(S)\right)(1-q)^{-1} \text { if such an } S \in[0,1] \text { exists, } \\ 1 & \text { otherwise. }\end{cases}
$$

Using the constraint to eliminate $x$ in the objective function of (D), the problem can be transformed into:

$$
\max _{0 \leqq S \leqq 1}(1-q) S(1-F(S))+q x_{2}(S)(1-F(S))+p \pi(S) F(S) .
$$

If $\hat{S}$ solves $(\mathrm{E})$, then $\hat{x}_{1}=(1-q) \hat{S}+q x_{2}(\hat{S})$ and $\hat{x}_{2}=x_{2}(\hat{S})$ are no-commitment equilibrium prices, and a $v$-buyer accepts the first offer if and only if $v \geqq \hat{S}$. The partial derivative with respect to $S$ of the objective function in $(\mathrm{E})$ is

$$
H(S, p, q) \equiv(1-q)\left(1-G^{\prime}(S)\right)+(p-q) x_{2}(S) f(S)+q x_{2}^{\prime}(S)(1-F(S)) .
$$

Since $0<p, q<1$,

$$
H(0, p, q)=1-q+q x_{2}^{\prime}(0)>0>-\left(1-q-(p-q) x_{2}(1)\right) f(1)=H(1, p, q),
$$

the objective function in $(\mathrm{E})$ attains a maximum for some $\hat{S}(p, q) \in(0,1)$ and

$$
H(\hat{S}(p, q), p, q) \equiv 0 .
$$

These results are summarized in Theorem 2 . 
Theorem 2. For fixed $p$ and $q$, the no-commitment equilibria are characterized by a triple $\left(\hat{x}_{1}(p, q), \hat{x}_{2}(p, q), \hat{S}(p, q)\right)$ such that $\hat{S}(p, q)$ solves $(\mathrm{E}), \hat{x}_{2}(p, q)=x_{2}(\hat{\boldsymbol{S}}(p, q))$, $\hat{x}_{1}(p, q)=(1-q) \hat{S}(p, q)+q \hat{x}_{2}(p, q)$, and a v-buyer accepts the first offer if and only if $v \geqq \hat{\boldsymbol{S}}(p, q)$. Furthermore $1>\hat{\boldsymbol{S}}(p, q)>\hat{\boldsymbol{x}}_{1}(p, q)>\hat{\boldsymbol{x}}_{2}(p, q)>0$.

Proof. Only the relationship $\hat{S}(\cdot)>\hat{x}_{1}(\cdot)>\hat{x}_{2}(\cdot)>0$ remains to be verified, but this follows since $S>x_{2}(S)$ implies $\hat{S}(\cdot)>\hat{x}_{2}(\cdot)$ and $\hat{x}_{1}(\cdot)$ is a convex combination of $\hat{S}(\cdot)$ and $\hat{x}_{2}(\cdot)$.

Therefore, in no-commitment equilibria, prices fall, sales are made in both periods with positive probability, and there is a positive probability that no sale will be made.

Also, since $H(S, p, q)$ is increasing in $p$, the equilibrium prices will be nondecreasing in $p$, and will be strictly increasing whenever the second-order condition for $(\mathrm{E})$ is satisfied strictly; if the seller becomes more patient then the buyer is made worse off.

No general statements can be made about how the no-commitment equilibrium prices change when $q$ changes, although decreases in $q$ are beneficial to the seller because a decrease in $q$ allows the seller to induce a given probability of a first-period sale with a higher first-period price. Another way to see this is to note that the objective function in (E) is decreasing in $q$.

It is difficult to make comparisons between the two types of equilibria. The seller prefers to be able to commit himself, of course, since the no-commitment equilibrium prices are feasible commitment strategies. For fixed $S$, the second price in a nocommitment equilibrium is lower than what the seller would charge if commitment is possible. This is because, with commitment, the seller can threaten to maintain a high price in order to induce first-period purchases. In the no-commitment equilibria, this threat is not credible. The next example is presented to show the difficulties of making a comparison and, in general, of carrying out sensitivity analysis. For tractability, we assume that the distribution of buyer reservation prices is discrete.

Example. The buyer's reservation price, $v$, is equally likely to take on the values $1, \frac{1}{2}+a$, and $a$, where $a$ is a small, positive number. The seller's reservation price is known to be zero. The equilibria for this example are described in Table I. Depending on the parameters, one of three strategies is an equilibrium: $(H, M)$, where first-period sales are made only if $v=1$ (high), and second-period sales are made only if $v=\frac{1}{2}+a$ (middle); $(M)$, where first-period sales are made if $v=1$ or $\frac{1}{2}+a$, and no sales are made in the second period; and $(M, L)$ where first-period sales are made if $v=1$ or $\frac{1}{2}+a$, and if $v=a$ (low) then a purchase is made in the second period. Strategy $(M)$ is feasible only if the seller can commit himself.

Given any $p^{0}$ and $q^{0}>0$ it is possible to find an $a>0$ such that $(H, M)$ is the no-commitment equilibrium for all $(p, q) \geqq\left(p^{0}, q^{0}\right)$. Since the buyer must wait until the second period for the price $\frac{1}{2}+a,(H, M)$ is strictly worse for him than the single-period equilibrium. Also, for $p \leqq q$, the seller strictly prefers his one-period profits to what he expects to make in the no-commitment equilibrium (this follows from Table I or Theorem 1). Here increasing the number of periods is bad for both bargainers since, in order to avoid charging a low price in the second period, the seller can only sell to a 1-buyer in the first period. This can only happen when the reservation price of the buyer takes on more than two values; Fudenberg and Tirole (1983) show that one of the bargainers prefers two periods to one when the buyer's reservation price takes on only two values.

For the commitment equilibrium, the example shows that increasing the length of the bargaining process can either increase (if $(H, M)$ is optimal) or decrease (if $(M, L)$ is optimal) the first price. An increase in $p$ can make the buyer better off (by reducing both prices) if it causes the strategy $(\boldsymbol{M}, L)$ to be optimal instead of $(\boldsymbol{M})$. Increases in 
TABLE I

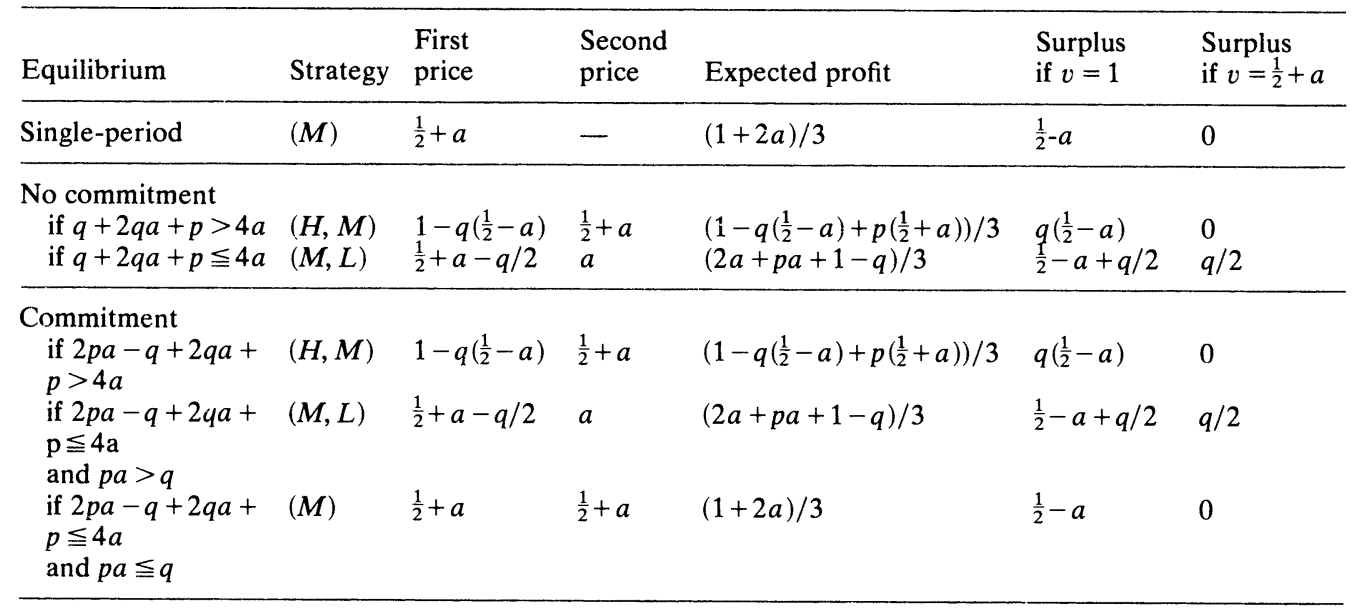

Note. An $a$-buyer never gets positive surplus.

$q$ make $(M, L)$ less attractive to the seller; this hurts the buyer because the alternative strategies are $(H, M)$ and $(M)$. The first price may be either higher or lower than the one-period price.

For the no-commitment equilibrium, it is also true that increases in the number of periods may either increase or decrease the first price. Furthermore, increases in $q$. may be unfavourable to the buyer by increasing both prices.

To compare the equilibria, note that $(H, M)$ can be the optimal no-commitment equilibrium while $(\boldsymbol{M})$ is optimal when commitment is possible. Thus the inability to make commitments may increase prices and thus reduce the buyer's surplus.

The example shows that in general, simply lengthening the bargaining process need not be beneficial to either bargainer. Theorem 3 presents a result that suggests, with appropriate controls on the environment, the one-shot result can be improved upon.

Our measure of bargaining efficiency is expected total surplus, $T(\cdot)$, the expected profits plus the expected surplus of the buyer. We restrict attention to the case $p=q$ so that second-period payoffs are comparable. When $p=q$, total surplus can be written

$$
T\left(S, x_{2}\right) \equiv p V\left(x_{2}\right)+(1-p) V(S),
$$

where

$$
V(x) \equiv x(1-F(x))+\int_{x}^{1}(v-x) F^{\prime}(v) d v
$$

is the expected total surplus if the single take-it-or-leave-it price $x$ is charged; (6) follows from (1), (3), and the definition of $V(\cdot),(7)$. In this context, the way to maximize the expected surplus is to give the object to the buyer, possibily requiring a lump-sum transfer from buyer to seller as well. This procedure guarantees ex post efficiency and no bargaining costs are incurred. However, it is not a feasible procedure if the seller has the right to set his sale price for then he would charge a positive price. The only way to guarantee ex post efficiency and a positive payoff to the seller would be to require the buyer to make a payment for the item independent of his reservation price. But if the buyer cannot be forced to make a lump-sum payment in excess of his valuation, it would not be possible to implement this procedure.

If attention is restricted to procedures that guarantee to the seller a certain profit level, a single take-it-or-leave-it price maximizes the buyer's surplus when $p=q$. To see 
this, use (1) and (3) to write the problem as:

subject to

$$
\max _{1 \geqq S \geqq x_{2} \geqq 0}(1-p) \int_{S}^{1}(v-S) F^{\prime}(v) d v+p \int_{x_{2}}^{1}(v-S) F^{\prime}(v) d v
$$

$$
(1-p) S(1-F(S))+p x_{2}\left(1-F\left(x_{2}\right)\right) \geqq K .
$$

Then, for some $\lambda \geqq 0$, problem (F) is equivalent to:

$$
\max _{1 \geqq S \geqq x_{2} \geqq 1}(1-p)(V(S)-(1-\lambda) S(1-F(S)))+p\left(V\left(x_{2}\right)-(1-\lambda) x_{2}\left(1-F\left(x_{2}\right)\right)\right),
$$

and, because the objective function is additively separable in $S$ and $x_{2},(\mathrm{G})$ has a solution that satisfies $S=x_{2}$. This is equivalent to setting a single price, $\tilde{x}^{4}{ }^{4}$ The problem with this procedure is that it is ex post inefficient and, unless future bargaining is prohibited or the seller can commit himself, the buyer will expect prices to fall in the future, and will refuse to purchase if his reservation price is slightly greater than $\tilde{x}$. However, if the bargaining is restricted to one period or commitment is possible, then the seller will set the price $\bar{x}$ that maximizes $x(1-F(x))$.

Is it possible to increase total surplus beyond $V(\bar{x})$ if the seller can set prices, but commitment is not possible? According to the next result, the answer is yes.

Theorem 3. If $G^{\prime \prime}(\cdot)$ is continuous and strictly positive, then the expected total surplus in a no-commitment equilibrium is maximized for p strictly between zero and one.

Remark 1. If a third party (arbitrator) can control the length of time between bargaining periods, or the number of offers, bargaining costs can be controlled. For example, the arbitrator can announce the probability of letting the bargainers meet again if they fail to reach an agreement in the first period. In this case, $p$ should be interpreted as the probability that the bargaining process will continue. Equivalently, he can vary the length of time between offers, shortening it if $p$ near one is desired, lengthening it if smaller $p$ is optimal.

Remark 2. In the proof of Theorem 3, the notation $\hat{S}(p) \equiv \hat{S}(p, p), \hat{x}_{2}(p) \equiv$ $\hat{x}_{2}(p, p)$, and $\hat{T}(p) \equiv T\left(\hat{\boldsymbol{S}}(p), \hat{x}_{2}(p)\right)$ is used. Also, $W(1) \equiv \lim _{p \rightarrow 1^{-}} W(p)$ for all functions $W(\cdot)$.

Proof. Since $H(S, p, p)=(1-p)\left(1-G^{\prime}(S)\right)+p x_{2}^{\prime}(S)(1-F(S))$, it follows that $H(S, 1,1)>0$ for all $S<1$. Thus, because $H(\cdot)$ is continuous, $H(S, p, p)=0$ has a unique solution for $p$ near one, hence $\hat{S}$ is characterized by (5). It follows that

$$
\hat{S}(1)=1 \text {. }
$$

Therefore,

$$
\hat{x}_{2}^{\prime}(1)=x_{2}^{\prime}(1) \hat{S}^{\prime}(1)=1 \text {. }
$$

The first equality follows because $\hat{x}_{2}(p) \equiv x_{2}(\hat{S}(p))$ and the second equality follows from (8) and an application of the implicit function theorem to (4). To prove the theorem, it suffices to show that $\hat{T}^{\prime}(1)<0$. This condition is sufficient because $(8)$ implies that no sales are made in the first period when $p=1$, and so $\hat{T}(1)=V(\bar{x})$, the single-period total expected surplus.

From $(6), \hat{T}(p) \equiv p V\left(\hat{x}_{2}(p)\right)+(1-p) V(\hat{S}(p))$. Therefore, since $V(1)=0$ and, because $\hat{x}_{2}(1)$ maximizes $x(1-F(x))$,

$$
V^{\prime}\left(\hat{x}_{2}(1)\right)=-\left(1-F\left(\hat{x}_{2}(1)\right)\right),
$$


it follows that

$$
\begin{aligned}
\hat{T}^{\prime}(1) & =V\left(\hat{x}_{2}(1)\right)+V^{\prime}\left(\hat{x}_{2}(1)\right) \\
& =\hat{x}_{2}(1)\left(1-F\left(\hat{x}_{2}(1)\right)\right)+1-\hat{x}_{2}(1)-\int_{\hat{x}_{2}(1)}^{1} F(v) d v-\left(1-F\left(\hat{x}_{2}(1)\right)\right)<0,
\end{aligned}
$$

where the first equality uses (9); the second equality uses (10) and an equivalent version of $V(\cdot)$ obtained by integration by parts; and the inequality follows since $\int_{x}^{1} F(v) d v>$ $F(x)(1-x)$ for $x<1$.

The proof of Theorem 3 shows that total surplus is not maximized when $p=q=1$. Increases in $p$ in the neighbourhood of $p=1$ have two effects on total surplus: a direct effect, which increases surplus by reducing bargaining costs, and an indirect effect, which decreases surplus by increasing $x_{2}$. At $p=1$, the direct effect is

$$
\hat{x}_{2}(1)\left(1-F\left(\hat{x}_{2}(1)\right)\right)+\int_{\hat{x}_{2}(1)}^{1}\left(v-\hat{x}_{2}(1)\right) F^{\prime}(v) d v,
$$

the total surplus, and is bounded above by $1-F\left(\hat{x}_{2}(1)\right)$, which would be the total surplus if $\hat{x}_{2}(1)$ were the price and all buyer types who purchased valued the object at $v=1$. The indirect effect comes only through the reduction in the buyer's expected surplus; this contribution is $-\left(1-F\left(\hat{x}_{2}(1)\right)\right) \hat{x}_{2}^{\prime}(1)$. Therefore, total surplus will not be maximized at $p=1$ when $\hat{x}_{2}^{\prime}(1) \geqq 1$. This is not true in the example given earlier, as the second price is constant near $p=1$ and, in fact, the conclusion of the theorem does not hold for the example. However, $\hat{x}_{2}^{\prime}(1)=1$ whenever $G^{\prime \prime}(\cdot)>0$ because then $\hat{x}_{2}(\cdot)$ is characterized by (5) for $p$ near 1 . When $p=q$, increasing $S$ has two effects on profit: it reduces first-period profit by causing the probability of a sale to decrease (the magnitude of this effect is $(1-p) S f(S)$ ), and it increases profit by allowing $x_{1}$ to increase (this effect is $\left[(1-p)+p x_{2}^{\prime}(S)\right](1-F(S))-$ the change in $x_{1}$ multiplied by the probability of a firstperiod sale). Since $\hat{S}(1)=1$, at $p=1 f(1)$ is the rate of change with respect to $p$ of the first effect. The analogous quantity for the second effect is $-\hat{x}_{2}^{\prime}(1) f(1)$. Since these two effects must cancel out at the optimum, $\hat{x}_{2}^{\prime}(1)=1$.

Since, when $p=q=0$, the bargaining is essentially restricted to one period and, when $p=q=1$, it is always possible for the seller to restrict sales to the second period by charging a high price in the first period, it follows from Theorem 1 that $\hat{T}(0)=\hat{T}(1)=$ $\bar{x}(1-F(\bar{x}))+\int_{\bar{x}}^{1}(v-\bar{x}) F^{\prime}(v) d v$, where $\bar{x}$ solves: $\max x(1-F(x))$. Theorem 3 asserts only that $\hat{T}(p)>\hat{T}(0)$ for some $0<p<1$. It would be of interest to know when $\hat{T}(p)$ is actually minimized at $p=0$ or 1 . This is the case if $F(v)=v^{m}, m>0$, but we have been unable to find more general conditions. In fact, $\hat{T}^{\prime}(0)>0$ if and only if $\hat{x}_{1}^{\prime}(0)<0$ (since changes in $p$ near zero have only a second-order effect on profit and the buyer's expected surplus depends, up to first order, only on $x_{1}$ ), but our assumptions do not imply $\hat{x}_{1}^{\prime}(0)<0$ and we have been unable to find a meaningful assumption that does guarantee that $\hat{x}_{1}^{\prime}(0)<0$.

We close this section by a particularly well-behaved example.

Example. Let $F(v) \equiv v$ for $0 \leqq v \leqq 1$ and assume that the seller's reservation price is known to be zero. When the discount factor of both bargainers is equal to $p$, the no-commitment equilibrium values are:

$$
\begin{aligned}
\hat{\boldsymbol{x}}_{1}(p) & =(2-p)^{2}(4-3 p)^{-1} / 2 \\
\hat{x}_{2}(p) & =(2-p)(4-3 p)^{-1} / 2 \\
\hat{\boldsymbol{S}}(p) & =(2-p)(4-3 p)^{-1}
\end{aligned}
$$




$$
\begin{aligned}
& \hat{\pi}(p)=\text { Expected Profits }=(2-p)^{2}(4-3 p)^{-1} / 4 \\
& \hat{B}(p)=\text { Expected Buyer Surplus }=\left(4-3 p^{2}\right)(4-3 p)^{-1} / 8 \\
& \hat{T}(p)=\text { Expected Total Surplus }=\left(12-8 p-p^{2}\right)(4-3 p)^{-1} / 8
\end{aligned}
$$

The commitment equilibrium values can be obtained from the no-commitment quantities with $p=0$ or 1 . The take-it-or-leave-it price is $\frac{1}{2}$, seller's expected profit is $\frac{1}{4}$, and the buyer's expected surplus is $\frac{1}{8}$. In this example, $\hat{T}^{\prime}(p), \hat{S}^{\prime}(p)$, and $-\hat{\pi}^{\prime}(p)$ have the same sign for all $p$ : buyer surplus is perfectly correlated with total surplus, and negatively correlated with expected profit. $\hat{T}(\cdot)$ is maximized when $p=\frac{2}{3}$, and minimized when $p=0$ or 1 . We can compare the total surplus generated by the mechanisms discussed in this section:

total surplus at single take-it-or-leave-it price $\left(x=\frac{1}{2}\right)=\frac{3}{8}$

total surplus maximizing no-commitment equilibrium $\left(p=\frac{2}{3}\right)=\frac{7}{18}$

total surplus at single price that yields expected profit equal to surplus maximizing no-commitment equilibrium $\left(x=\frac{1}{3}\right)=\frac{4}{9}$

total available surplus $(x=0)=\frac{1}{2}$

Thus, total surplus can be increased from the single take-it-or-leave-it price if the bargainers are informed that negotiations will continue with probability $\frac{2}{3}$ if they fail to reach an agreement with the first offer. However, this procedure is dominated by a single price of $\frac{1}{3}$, which guarantees the seller the same profit as the no-commitment equilibrium with $p=\frac{2}{3}$, but increases the buyer's expected surplus since no costs are incurred. Finally, total surplus is maximized if the price is set at zero. The last two procedures are not feasible if the seller has the right to set prices.

\section{INFINITE HORIZON}

Thus far we have assumed that bargaining ends after two periods. It would be more realistic to assume that in each period there is another price offered by the seller and a response by the buyer. As is apparent from Section 3, there is no guarantee that the concavity of a single-period profit function will be inherited in a multi-period model. Consequently, the dynamic programming techniques used to construct an equilibrium do not apply. ${ }^{5}$ However, existence results are available for models that are similar to ours. In particular, Goldman's (1980) proof of existence of intertemporally consistent plans can be modified to guarantee existence in our model for any finite number of bargaining periods. However, there appears to be no simple, general method to guarantee uniqueness, and doing comparative statics would be difficult. On the other hand, a class of distribution functions lend themselves to analysis.

We shall consider the class of distribution functions for the buyer's reservation price $v$ of the form $F(v, m) \equiv v^{m}$ for $m>0$ and $0 \leqq v \leqq 1$. The seller's reservation price is assumed to be 0 . This class is simple enough to yield analytically tractable results, yet rich enough to allow for comparisons. For each $m$ the mean of $F(\cdot, m)$ is $m(m+1)^{-1}$ but increases in $m$ make the distribution of reservation prices less spread-out and therefore correspond in a natural way to decreases in the seller's uncertainty about the buyer's reservation price. ${ }^{6}$ Thus, after correcting for the difference in means, we are able to analyse how increasing uncertainty affects bargaining outcomes.

We begin by analysing commitment equilibria. That is, we look for prices $x_{i}$, $i=1,2, \ldots$ that maximize the seller's expected profits assuming that the buyer, taking prices as given, buys in the period that maximizes his discounted surplus. 
Theorem 5. The seller's optimal commitment strategy is of the form

$$
x_{i}^{*}(p, q, m)=\left(c^{*}(p, q, m)\right)^{i-1} x_{1}^{*}(p, q, m) \text { for } i=1,2, \ldots
$$

where $x_{1}^{*}(p, q, m)=(m+1)^{-1 / m}, c^{*}(p, q, m)=1$ for $p \leqq q$ and, when $p>q, c^{*}(\cdot)$ is defined implicitly by

$$
p\left(1-q c^{*}\right)\left(1-\left(c^{*}\right)^{m}\right) \equiv m\left(1-p c^{*}\right)\left(p\left(c^{*}\right)^{m}-q\right)
$$

and

$$
x_{1}^{*} \equiv(m+1)^{-1 / m}(1-q)\left(1-q c^{*}\right)^{-1}\left[\left(1-p\left(c^{*}\right)^{m+1}\right)\left(1-p c^{*}\right)^{-1}\right]^{1 / m} .
$$

Expected profit, $\pi^{*}(\cdot)$, is given by

$$
\pi^{*}(p, q, m)=x_{1}^{*}(p, q, m) m(m+1)^{-1} .
$$

Proof. For $p \leqq q$, the argument of Theorem 1 can be extended to show that the seller will restrict sales to a single period, and charge $\bar{x}(m) \equiv(m+1)^{-1 / m}$, the expected profit maximizing single-period price. All other prices should be greater than or equal to $\bar{x}(m)$ in order to restrict sales to the first period. Without loss of generality, we may take $x_{i}^{*}(p, q, m)=\bar{x}(m)$ for $i>1$.

For $p>q$, the seller's maximization problem is to find $x_{1}, x_{2}, \ldots$ to solve:

$$
\max \sum_{i=1}^{\infty} p^{i-1} x_{i}\left(F\left(S_{i-1}, m\right)-F\left(S_{i}, m\right)\right)
$$

subject to

$$
S_{i}= \begin{cases}\left(x_{i}-q x_{i+1}\right)(1-q)^{-1} & \text { if } i \geqq 1, \\ 1 & \text { if } i=0\end{cases}
$$

and

$$
S_{i-1} \geqq S_{i} \geqq 0 \quad \text { for } i=1,2, \ldots .
$$

The first-order conditions for $(H)$ are:

$$
0=F\left(S_{0}, m\right)-F\left(S_{1}, m\right)-f\left(S_{1}, m\right)\left(x_{1}-p x_{2}\right)(1-q)^{-1}
$$

and

$$
\begin{aligned}
0= & p\left(F\left(S_{i-1}, m\right)-F\left(S_{i}, m\right)\right)+q f\left(S_{i-1}, m\right)\left(x_{i-1}-p x_{i}\right)(1-q)^{-1} \\
& -p f\left(S_{i}, m\right)\left(x_{i}-p x_{i+1}\right)(1-q)^{-1} \text { for } i=2,3, \ldots
\end{aligned}
$$

Here $f(v, m) \equiv \partial F(v, m) / \partial v$. These conditions determine a difference equation. The values for $x_{i}^{*}(\cdot)$ in the statement of the theorem solve the difference equation and, since $0 \leqq c^{*}(\cdot) \leqq 1$, the constraints of $(\mathrm{H})$ are satisfied. It can be checked that $x_{1}^{*}(\cdot), x_{2}^{*}(\cdot), \ldots$ satisfy the sufficient conditions for maximization of $(\mathrm{H})$. The formula for $\pi^{*}(\cdot)$ is easily derived given $x_{i}^{*}(\cdot)$ and $c^{*}(\cdot)$.

When $p>q$, increases in $q$ lower the expected profits of the seller because any strictly decreasing price schedule becomes less profitable when the buyer becomes more patient; a tedious computation shows that increases in $p$ lower the expected surplus of the buyer, but need not make all buyer types worse off: the prices may fall faster if $p$ increases, increasing the surplus of low- $v$ buyers. Another computation shows that increases in $m$ increase prices, so that the buyer prefers low to high values of $m$. This can be explained because the mean of $F(\cdot)$ increases with $m$. Thus there is more reason to charge a high price as $m$ increases. We have been unable to determine the effect that increases in $m$ have on the expected surplus of the buyer when a correction for changes in mean is made; $\pi^{*}(p, q, m) m^{-1}(m+1)$, the expected profit relative to the mean of $F(\cdot, m)$, increases with $m$, so mean-preserving spreads in the distribution of buyer reservation prices lower the seller's profit. 
Next we characterize the no-commitment equilibria. Let $\hat{\pi}_{n}(S, p, q, m)$ be the expected profit when $n$ periods remain and the buyer is known to have a reservation price no greater than $S$, and let $\hat{r}_{n}(S, p, q, m)$ be the price charged in the first of the remaining periods. For notational convenience, we suppress functional dependence on $p, q$, and $m$; no confusion should arise.

Theorem 6. For fixed $p, q$, and $m$, the no-commitment equilibrium of the $n$-stage bargaining game has expected profit, $\hat{\pi}_{n}(S)$, and price (with $n$ periods remaining), $\hat{r}_{n}(\cdot)$, given by

$$
\begin{gathered}
\hat{r}_{n}(\boldsymbol{S})=\hat{c}_{n} S \\
\hat{\pi}_{n}(S)=m(m+1)^{-1} \hat{c}_{n} S
\end{gathered}
$$

where

$$
\begin{gathered}
\hat{c}_{1}=(m+1)^{-1 / m} \text { and, for } m>1, \\
\hat{c}_{n}=\left(1-q+q \hat{c}_{n-1}\right)\left[\left(1-q+q \hat{c}_{n-1}\right)\left((m+1)\left(1-q+q \hat{c}_{n-1}\right)-m p \hat{c}_{n-1}\right)^{-1}\right]^{1 / m} .
\end{gathered}
$$

Proof. The proof is by induction on $n$. When one period remains, we solve:

$$
\max _{x} x\left[S^{m}-x^{m}\right] S^{-m}
$$

so that

$$
\hat{r}_{1}(\boldsymbol{S})=(m+1)^{-1 / m} \boldsymbol{S} \quad \text { and } \quad \hat{\pi}_{1}(\boldsymbol{S})=m(m+1)^{-1}(m+1)^{-1 / m} \boldsymbol{S} .
$$

In general,

$$
\hat{\pi}_{n}(S) \equiv \max _{x}\left(x\left(S^{m}-T^{m}\right)+p \hat{\pi}_{n-1}(T) T^{m}\right) S^{-m},
$$

where

$$
T-x=q\left(T-\hat{r}_{n-1}(T)\right) .
$$

In order to complete the proof by induction, assume that

$$
\hat{\pi}_{n-1}(T)=m(m+1)^{-1} \hat{c}_{n-1} T \text { and } \hat{r}_{n-1}(T)=\hat{c}_{n-1} T .
$$

Substituting the constraint into the objective function of (12), and using the induction hypothesis, (13), it is possible to rewrite (12) as

$$
\hat{\pi}_{n}(S) \equiv \max _{T}\left[\left(1-q+q \hat{c}_{n-1}\right) T\left(S^{m}-T^{m}\right)+p m(m+1)^{-1} \hat{c}_{n-1} T^{m+1}\right] S^{-m} .
$$

The unique maximum is attained when

$$
\left((m+1)\left(1-q+q \hat{c}_{n-1}\right)-m p \hat{c}_{n-1}\right) T^{m}=\left(1-q+q \hat{c}_{n-1}\right) S^{m},
$$

so

$$
T=\left[\left(1-q+q \hat{c}_{n-1}\right)\left((m+1)\left(1-q+q \hat{c}_{n-1}\right)-m p \hat{c}_{n-1}\right)^{-1}\right]^{1 / m} S .
$$

Using (13) and (14), we obtain $\hat{r}_{n}(S)=\hat{c}_{n} S$ and $\hat{\pi}_{n}(S)=m(m+1)^{-1} \hat{c}_{n} S$, completing the proof.

Several sensitivity results can be derived from Theorem 6: decreases in $p$ lowers prices, therefore the buyer benefits; decreases in $q$ benefit the seller; increases in $m$ lead to higher prices, making the buyer worse off; also, increases in $m$ increase the expected profits of the seller relative to the mean. These facts can be derived from straightforward, but tedious, computations.

Increases in the number of bargaining periods also has a definite effect. It follows from Theorem 6 that $\hat{\pi}_{n}(\cdot)$ is proportional to $\hat{c}_{n}(\cdot)$. Moreover, the sequence $\left\{\hat{c}_{n}\right\}$ is 
monotonic. If $p$ is much bigger than $q$, then the sequence increases, thus a relatively patient seller prefers a longer bargaining horizon. In this case, the effect on the buyer is ambiguous: if $v$ is high, then the buyer faces higher prices in the time periods relevant to him, but increasing the number of periods increases the probability that the buyer will obtain positive surplus.

The expected surplus for the $n$-stage, no-commitment equilibrium when $v \leqq S$ is given by $\hat{B}_{n}(S)=\hat{k}_{n} S$, where, setting

$$
\begin{gathered}
h(c)=\left[(1-q+q c)((m+1)(1-q+q c)-m p c)^{-1}\right]^{1 / m}, \\
k_{1}=m(m+1)^{-1}-\hat{c}_{1}+\hat{c}_{1}^{m+1}(m+1)^{-1}
\end{gathered}
$$

and

$$
\begin{aligned}
\hat{k}_{i+1}= & m(m+1)^{-1}\left(1-h\left(\hat{c}_{i}\right)^{m+1}\right)+\left(1-q+q \hat{c}_{i}\right)\left(h\left(\hat{c}_{i}\right)^{m+1}-h\left(\hat{c}_{i}\right)\right) \\
& +q \hat{k}_{i} h\left(\hat{c}_{i}\right)^{m+1} \text { for } i>1 .
\end{aligned}
$$

The sequence $\left\{\hat{k}_{n}\right\}$ increases whenever $\left\{\hat{c}_{n}\right\}$ is decreasing, as is to be expected since in this case surplus increases for each $v$. In general $\left\{\hat{k}_{n}\right\}$ need not be monotonic. It can be shown that $\hat{k}_{n-1}>\hat{k}_{n}$ implies that $\hat{k}_{n}>\hat{k}_{n+1}$, but it may happen that the sequence $\left\{\hat{k}_{n}\right\}$ increases and then falls. This occurs when $p$ is large relative to $q$ (but not so large that $\left\{\hat{k}_{n}\right\}$ decreases monotonically). An increase in $n$ has two effects: it increases the price charged to all buyer types who buy before the last period and increases the probability of sales. The first effect becomes larger relative to the second when $n$ increases as sales are made with higher probability in that case, and the potential surplus available by increasing the probability of a sale is small. Except for the rare case when $\left\{\hat{c}_{n}\right\}$ is constant (this requires that $p$ and $q$ satisfy

$$
(m+1)\left(1-q+q \hat{c}_{1}\right)-m p \hat{c}_{1}=(m+1)\left(1-q+q \hat{c}_{1}\right)^{m+1}
$$

where $\left.\hat{c}_{1}=(m+1)^{-1 / m}\right),\left\{\hat{c}_{n}\right\}$ is strictly decreasing for all other values of $p$ and $q$, so that increasing the number of periods benefits the buyer and hurts the seller.

In order to compare the two solution concepts, we take the limit of the $n$-stage no-commitment equilibria. ${ }^{7}$ Since the sequence $\hat{c}_{n}(\cdot)$ is monotonic in $n$ and hence converges to a limit, $\hat{c}(\cdot)$, the next result follows immediately from Theorem 6 .

Corollary. The no-commitment equilibria of the infinite horizon model are characterized by prices $\hat{x}_{i}(p, q, m)=\hat{c}(p, q, m)(\hat{d}(p, q, m))^{i-1}$, where $\hat{d}=\hat{c}(1-q+q \hat{c})^{-1}$ and $\hat{c}(\cdot)$ is defined implicitly by

$$
\hat{c} \equiv(1-q+q \hat{c})\left[(1-q+q \hat{c})((m+1)(1-q+q \hat{c})-m p \hat{c})^{-1}\right]^{1 / m} .
$$

Expected profits, $\hat{\pi}(p, q, m)$, are equal to $m(m+1)^{-1} \hat{c}(p, q, m)$.

Thus, the general form of the prices for the two types of equilibrium is identical in that the ratio of successive periods' prices is independent of the period. A routine computation shows that $\hat{x}_{i}(\cdot)<x_{i}^{*}(\cdot)$ for all $i$, so that the ability to make commitments leads to strictly higher prices in this class of examples. Since $0<\hat{c}(\cdot)<1, \lim _{i \rightarrow \infty} \hat{x}_{i}(\cdot)=$ 0 , so that bargaining outcomes in the no-commitment equilibria are efficient ex post; this will be the case for commitment equilibria as well if and only if $p>q$.

For the no-commitment equilibrium, when $p=q$, it can be shown that total surplus and the expected surplus of the buyer increase with equal increases in the discount factors, and that all of the possible surplus is obtained (and goes to the buyer) when $p$ and $q$ approach one. Thus, as bargaining costs go to zero in the infinite horizon model, the seller loses the ability to make sales at positive prices.

The examples discussed in this section are extremely well-behaved. The reason for this is that $m$ is homogeneous in $v$. Therefore, the seller's problem is the same, up to 
a uniform rescaling, for any cut-off value. When an offer is refused, the seller learns something about the buyer's reservation price (that it is below a certain value), but that does not change the form of his pricing strategy. This amounts to a stationarity restriction that makes the infinite horizon dynamic programming problem tractable.

\section{CONCLUSION}

The simple model of this paper was presented in an attempt to capture several important elements of bargaining: the effects of uncertainty; the sequential nature; the possibility of impasses; the sensitivity to bargaining costs; the manner in which information is transferred; and the dependence on whether or not commitment is possible. To the extent that the model is an accurate representation of bargaining situations the results seem to indicate that detailed statements about the effects that changes in the parameters have on outcomes cannot be made without additional assumptions, although there is a presumption that control of the timing and number of offers can improve results.

In particular, we found that the ability to make commitments was beneficial to the seller, but little else could be said in general. Lengthening the bargaining horizon could hurt both players, although the bargaining environment can be modified to increase expected surplus. Making one bargainer more impatient need not improve the welfare of the other if commitment is not possible as it may make attractive strategies infeasible. Only for the well-behaved examples of Section 5 could definite conclusions be made. Here intuition was generally correct: increasing uncertainty hurt the seller and bargainers typically preferred to bargain against an opponent with high costs of waiting.

Two limitations of the model are worth mentioning. Although comparison of expected payoffs in commitment equilibria to those in no-commitment equilibria gives a measure of the incentives the seller has to attempt commitment, it would be more satisfying if the ability to make commitments were derived endogenously. It may be possible to do this by deriving the costs of making commitments and carrying out an analysis along the lines of Crawford (1982). For example, commitment should be relatively likely (less costly) when the difference between the profit expected from using conditionally optimal prices and commitment prices is relatively small in all future periods.

Another problem is the structure of bargaining we assumed. Ideally, both the buyer and the seller should be allowed to make offers with asymmetries in their roles determined endogenously. Some of our results are sensitive to the assumption that the seller only makes offers. In particular, the assumption restricts the way in which the seller can learn about the buyer.

First version received November 1980; final version accepted January 1983 (Eds.)

We are grateful to Vincent Crawford, Drew Fudenberg, Luis Guasch, Eric Maskin, Jean Tirole, two anonymous referees, and participants in seminar presentations at UCLA and a Stanford IMSSS Workshop for helpful comments. While we became aware of the work of Fudenberg and Tirole after the first version of this paper was written, we benefited greatly from reading their treatment of a nearly identical problem. Their influence appears throughout our paper. Sobel's work was partially supported by the SSRC through the project "Incentives, Consumer Uncertainty, and Public Policy" and Takahashi's work was supported in part by NSF grant SES 79-05550.

\section{NOTES}

1. An earlier version of this paper treated the case in which the seller's reservation price was unknown. The analysis follows that of Milgrom and Roberts (1982) and the results are similar to those of Fudenberg and Tirole (1983), which contains a detailed discussion of this case.

2. This assumption will be made throughout the paper. However, the definition of no-commitment equilibria can be extended to the case in which the maximum of $x(F(S)-F(x))$ is attained at more than one point. 
3. The equilibrium concept is a refinement of Harsanyi's (1967)-(1968) notion of Bayesian Nash equilibrium along the lines of Selten's (1975) concept of subgame perfection. However, the game has no proper subgames; the seller can make inferences about the buyer's reservation price on the basis of a refusal to make a purchase, but he cannot assign a prior distribution to $v$ at a particular stage of the game without reference to previous actions. The inclusion of a specification of beliefs along with strategies in the definition of equilibrium is due to Kreps and Wilson (1982).

4. Arguments of Maskin and Riley (1980) or Riley and Zeckhauser (1980) can be used to derive a more general version of this result. We are grateful to a referee for clarifying our ideas on this point.

5. This observation, in the context of dynamic consistency, was first made by Peleg and Yaari (1973).

6. We refer to the Rothschild-Stiglitz (1970) definition of risk. Each member of the family of distributions $F(v, m) \equiv\left[(m+1) m^{-1}\right]^{-m} v^{m}$ on $0 \leqq v \leqq(m+1) m^{-1}$ has mean one, and risk decreases as $m$ increases.

7. Fudenberg and Levine (1981) give conditions under which the limit of $\varepsilon$-perfect equilibria for finite horizon games is a perfect equilibrium for an infinite horizon game. Fudenberg (1981) indicates that these results generalize to the solution concept of this paper. This implies that the limit of our finite horizon equilibria is a no-commitment equilibrium of the infinite horizon game.

\section{REFERENCES}

BINMORE, K. (1980), "Nash Bargaining Theory: II" (London School of Economics I.C.E.R.D. Discussion Paper 80/14).

CHATTERJEE, K. and SAMUELSON, W. (1981), "The Simple Economics of Bargaining" (Boston University, School of Management, Working Paper 2/81).

CRAMPTON, P. C. (1982), "Bargaining with Incomplete Information” (Stanford University Graduate School of Business, Research Paper 652).

CRAWFORD, V. P. (1982), “A Theory of Disagreement in Bargaining”, Econometrica, 50, 607-637.

FUDENBERG, D. (1981), private communication.

FUDENBERG, D. and LEVINE, D. (1981), "Perfect Equilibria of Finite and Infinite Horizon Games" (M.I.T. mimeo).

FUDENBERG, D and TIROLE, J. (1983), "Sequential Bargaining with Incomplete Information”, Review of Economic Studies, $\mathbf{5 0}$.

GOLDMAN, S. M. (1980), “Consistent Plans", Review of Economic Studies, 47, 534-537.

HARSANYI, J. C. (1967-68), "Games with Incomplete Information Played by 'Bayesian' Players, I-III", Management Science, 14, 159--82, 320-34, 486-502.

KREPS, D. and WILSON, R. (1982), "Sequential Equilibria”, Econometrica, 50, 863-894.

MCLENNAN, A. (1981), "A General Noncooperative Theory of Bargaining" (University of Toronto mimeo).

MASKIN, E. and RILEY, J. (1980), "Auctioning an Indivisible Object” (Discussion Paper, Kennedy School of Government, Harvard University).

MILGROM, P. and ROBERTS J. (1982), "Limit Pricing and Entry Under Incomplete Information: An Equilibrium Analysis", Econometrica, 50, 443-459.

MYERSON, R. B. (1979), "Incentive Compatibility and the Bargaining Problem", Econometrica, 47, 61-73.

MYERSON, R. B. and SATTERTHWAITE, M. A. (1983), "Efficient Mechanisms for Bilateral Trading", Journal of Economic Theory.

PELEG, B. and YAARI, M. (1973), "On the Existence of a Consistent Course of Action when Tastes are Changing", Review of Economic Studies, 40, 391-401.

RILEY, J. G. and ZECKHAUSER, R. (1980), "Optimal Selling Strategies, When to Haggle, When to Hold Firm" (Discussion Paper, Kennedy School of Government, Harvard University).

ROSENTHAL, R. W. (1978), "Arbitration of Two-Party Disputes under Uncertainty", Review of Economic Studies, 45, 595-604.

ROTHSCHILD, M. and STIGLITZ, J. (1970), “Increasing Risk: I. A Definition”, Journal of Economic Theory, 2, 225-243.

RUBINSTEIN, A. (1982), "Perfect Equilibrium in a Bargaining Model", Econometrica, 50, 97-109.

SAMUELSON, W. (1980), "First Offer Bargains", Management Science, 26, 155-164.

SELTEN, R. (1975), "Reexamination of the Perfectness Concept for Equilibrium Points in Extensive Games", International Journal of Game Theory, 4, 25-55.

STOKEY, N. L. (1979), "Intertemporal Price Discrimination", The Quarterly Journal of Economics, 93, 355-371. 